This PDF is a selection from an out-of-print volume from the National Bureau of Economic Research

Volume Title: Anticipations and Purchases: An Analysis of Consumer Behavior

Volume Author/Editor: F. Thomas Juster

Volume Publisher: Princeton University Press

Volume ISBN: 0-87014-079-5

Volume URL: http://www.nber.org/books/just64-1

Publication Date: 1964

Chapter Title: An Empirical Analysis of Buying Intentions and Subsequent Purchases

Chapter Author: F. Thomas Juster

Chapter URL: http://www.nber.org/chapters/c1030

Chapter pages in book: ( $17-42)$ 
CHAPTER 2

\section{An Empirical Analysis of Buying Intentions and Subsequent Purchases}

\section{Introduction}

THE Consumers Union reinterview survey was specifically designed for an analysis of purchase rates of households that had reported buying intentions. Not only are data on intentions and purchases available for a large number of individual products, but the survey contains alternative sets of questions about intentions. The original sample was randomly divided into five subsamples; households in each subsample were sent questionnaires identical in all respects except for the question(s) dealing with buying intentions. This design served two purposes: the feasibility of designing an "optimal" intentions question could be judged, and the performance of experimental intentions questions could be compared with that of questions similar to those currently in use on other surveys. Given this design,

TABLE 1

Intentions Questions Used in Consumers Union Reinterview Survey, APRIL, 1958

\begin{tabular}{|c|c|c|}
\hline $\begin{array}{l}\text { Subsample } \\
\text { Designation }\end{array}$ & $\begin{array}{l}\text { Intentions } \\
\text { Question } \\
\text { Designation }\end{array}$ & Intentions Question \\
\hline \multirow[t]{2}{*}{ A } & $\mathbf{A}_{1}$ & $\begin{array}{l}\text { Which of the following products do you definitely plan } \\
\text { to buy over the next } 12 \text { months or so? }\end{array}$ \\
\hline & $\mathbf{A}_{2}$ & $\begin{array}{l}\text { Which . . products will you probably or possibly buy } \\
\text { over the next } 12 \text { months or so? }\end{array}$ \\
\hline \multirow[t]{2}{*}{ B } & $\mathbf{B}_{1}$ & $\begin{array}{l}\text { Which }{ }_{\text {months? }} \text { products do you plan to buy within } 6 \\
\text { mo }\end{array}$ \\
\hline & $\mathbf{B}_{2}$ & Which ... products do you plan to buy later? \\
\hline \multirow[t]{2}{*}{ C } & $\mathrm{G}_{1}$ & $\begin{array}{l}\text { Which . . products do you plan to buy over the next } \\
12 \text { months or so? }\end{array}$ \\
\hline & $\mathrm{C}_{2}$ & $\begin{array}{l}\text { Which . . products do you plan to buy over the next } \\
12 \text { months or so if your family income during this } \\
\text { period were to be } 10 \text { to } 15 \text { per cent higher than you } \\
\text { now expect? }\end{array}$ \\
\hline $\mathfrak{a}$ & $\mathrm{C}_{3}$ & $\begin{array}{l}\text { Which... products do you plan to buy over the next } \\
12 \text { months or so if your family income during this } \\
\text { period were to be } 10 \text { to } 15 \text { per cent lower than you now } \\
\text { expect? }\end{array}$ \\
\hline $\mathbf{D}$ & $\mathrm{D}_{\mathbf{1}}$ & $\begin{array}{l}\text { Which . . products do you plan to buy over the next } \\
12 \text { months or so? }\end{array}$ \\
\hline \multirow[t]{2}{*}{$\mathbf{E}$} & $\mathbf{E}_{1}$ & $\begin{array}{l}\text { Which } . . . \text { products do you plan to buy before next } \\
\text { October? }\end{array}$ \\
\hline & $\mathbf{E}_{2}$ & $\begin{array}{l}\text { Which ... products do you plan to buy between } \\
\text { October and a year from now? }\end{array}$ \\
\hline
\end{tabular}

Source: Consumer Purchases Study, NBER. 
purchase rates for all households should vary'only at random among the five subsamples. But purchase rates for intenders and nonintenders should vary systematically among the subsamples, depending on the characteristics of the particular set of intentions questions asked.

The five sets of intentions questions are listed in Table 1. Of these, data are presented and analyzed for all but the $E_{1}, E_{2}$, and $C_{3}$ questions. The $\mathrm{E}_{2}$ question was systematically misinterpreted by a large fraction of respondents, and has never been fully processed; ${ }^{1} E_{1}$ turned out to be almost identical to $B_{1}$, as anticipated. The $C_{3}$ question was left blank by a very heavy majority of respondents, and my suspicion is that many did so because they found the question irrelevant to their own circumstances and therefore uninteresting. In addition, so few households reported intentions to buy that the cell sizes are quite small and the data behave erratically.

\section{Analysis of Intentions Questions}

Before turning to the empirical results, it will be useful to examine the structure of the intentions questions. ${ }^{2}$ It must be borne in mind that the

${ }^{1}$ See Juster, Consumer Expectations, Plans, and Purchases: A Progress Report, New York, NBER, 1959. Many respondents appear to have misread the phrase in $E_{2}$ "and a year from now" as saying "and a year from then."

2 On the questionnaire schedule, a number of commodities were listed below the question(s); as many columns as needed, with a brief heading that repeated the key words in the intentions question and a box for each commodity, formed the body of what was essentially a table. Respondents simply marked $X$ to indicate that they intended to buy a particular item. One of the five sets of questions, and the format, is shown below.

\section{RECENT PURCHASES AND BUYING PLANS}

Which of the following products have you bought in the past 12 months or so? (Column A) Which of the following products do you plan to buy over the next 12 months or so, and how certain are you of these plans? (Columns $\mathrm{B}$ and $\mathrm{C}$ )

$\begin{array}{cccc} & & & \text { Probably or } \\ \text { Have } & \text { Definitely } & \text { Possibly } \\ \text { Broduct } & \text { A } & \text { Will Buy } & \text { Will Buy } \\ \text { A } & \text { B } & \text { C }\end{array}$

Air conditioner, room

Automobile, new

Less than $\$ 2,500$

$\$ 2,500-\$ 3,499$

$\$ 3,500$ and over

Automobile, used

Camera, movie

Carpets and rugs (over $\$ 100$ cost)

Clothes dryer

Dishwasher 
interpretation of the question is left entirely to the respondent, a necessity in any mail survey but generally also in personal interview surveys. The $A_{1}$ and $A_{2}$ questions are very similar to those used in the Survey of Consumer Finances (SCF) conducted by the University of Michigan's Survey Research Center and sponsored by the Federal Reserve Board until 1959. The time dimension specified by $\mathrm{A}_{1}$ and $\mathrm{A}_{2}$-next twelve months or so-is slightly more open ended than that specified by the SCF questions, which generally ask about prospective purchases during a calendar year in a survey taken early in the same year.

The $B_{1}$ question is similar to one of those asked on the quarterly survey of buying intentions currently conducted by the United States Bureau of the Census; the only apparent difference is that the Census question reads "expect to buy" instead of "plan to buy." The meaning of the $B_{2}$ question is difficult to judge. (This question was included mainly for comparability with a previous survey of the Consumers Union sample.) Taking the question literally (Which . . products do you plan to buy later?), any respondent under forty-five years of age would presumably check almost every product on the list. Most respondents did not do so; they apparently thought (sensibly enough!) that "later" must mean something like a couple of years but not indefinitely, and appear to have checked those commodities they had given some thought to purchasing or would like to buy if they could afford to do so.

The $C_{1}$ and $C_{2}$ questions are experimental, while the $D_{1}$ question is much the same as another of those now asked on the Census survey. Note that the $\mathrm{C}_{1}$ and $\mathrm{D}_{\mathbf{1}}$ questions, taken by themselves, appear to be absolutely identical; the wording of both is exactly the same. I have previously shown that the distribution of yes and no responses is not identical for $\mathrm{C}_{1}$ and $D_{1}$, and that the differences are systematic rather than random. ${ }^{3}$ The reason is, presumably, that the set of three questions given the $\mathrm{C}$ subgroup tends to reduce the dispersion among respondents in the interpretation of the phrase "plan to buy." The $\mathrm{C}_{1}$ question must be interpreted as meaning "What do you plan to buy if your income is as expected?," since $\mathrm{C}_{2}$ and $\mathrm{C}_{3}$ specifically ask about "buying plans if family income were to be higher (lower) than expected." But $D_{1}$ simply asks about plans to buy. While it is true that the most reasonable interpretation of $D_{1}$ is "What do you plan to buy, given your expectations?," some respondents are bound to interpret the question differently. And since $D_{1}$ respondents have only two choices-to check or not to check the box under the plan-

${ }^{3}$ See Juster, Consumer Expectations. 
to-buy column-the dispersion of what yes respondents actually had in mind must be greater in $D_{1}$ than in $C_{1}{ }^{4}$

Another illuminating comparison involves $D_{1}$ and the combination of $A_{1}$ and $A_{2}$. $D_{1}$ asks about plans to buy "over the next twelve months or so"; $\mathrm{A}_{1}$ asks respondents what they definitely will buy, $\mathrm{A}_{2}$ what they probably or possibly will buy, also "over the next twelve months or so." Thus the only difference is that $D_{1}$ says nothing at all about the certainty that is supposed to accompany a yes response while $A_{1}$ and $A_{2}$ are explicit on this score. ${ }^{5}$ The results show that the average respondent interprets the question "do you plan to buy?" when "plan" is not subject to any qualification, as implying a higher degree of certainty than the more specific question "will you definitely, probably, or possibly buy?"; substantially fewer respondents reported yes to the $D_{1}$ question than to the combination of $\mathrm{A}_{1}$ or $\mathrm{A}_{2}$.

\section{Empirical Findings}

The basic empirical results are summarized below in Table 2. Respondents have been divided into dichotomous (yes-no) classes based on the alternative intentions questions. Excluding the $E_{1}, E_{2}$, and $C_{3}$ questions for reasons already noted, seven dichotomous classifications can be constructed. The A subsample, for instance, yields two such classifications: A household either reports that it "definitely will buy"-a yes response to $A_{1}$ - or does not so report-a no response to $A_{1}$; alternatively, a household either reports that it definitely, probably, or possibly will buy-a yes response to either $A_{1}$ or $A_{2}-$ or does not so report-a no response to both $\mathrm{A}_{1}$ and $\mathrm{A}_{2}$.

In limiting the presentation of data to dichotomous distributions, it is clear that potentially useful information is ignored: Again using the A subsample for illustration, a classification into these three groups (definitely yes, probably-possibly yes, neither) is quite likely to be more useful than either of the dichotomous groupings shown in Table 2. However,

4 The data indicate that the proportion of respondents giving a more liberal interpretation to $D_{1}$ than to $C_{1}$, that is, those who would say yes if asked $D_{1}$ but no if asked $\mathrm{C}_{1}$, must have been larger than the proportion giving a more restrictive interpretation, since on balance relatively more households reported buying intentions on $\mathrm{D}_{1}$. There is no way to tell how large the gross differences are, since the data show only net differences (proportion interpreting $D_{1}$ more liberally than $C_{1}$ minus proportion interpreting $D_{1}$ as more restrictive than $C_{1}$ ).

"That is, $A_{1}$ and $A_{2}$ have explicit qualifying adjectives-"definitely" $\left(A_{1}\right)$ and "probably or possibly" $\left(A_{2}\right)$. I do not imply that all respondents interpret these adjectives in the same way. In fact, one of the conclusions of this study is that these verbal proxies for degree of certainty may be a major source of error in using intentions data for prediction. 
the dichotomous groupings bring out some interesting points, and more refined groupings are examined in Chapter 3.

\section{ORGANIZATION OF BASIG DATA}

The basic data table is divided into thirteen sections, one for each of the commodities analyzed. ${ }^{6}$ The stub lists the seven intender-nonintender (yes-no) classifications available from the data. The classifications are designated by the nomenclature used above to denote the intentions questions. The classification labeled $A_{1}$, for example, divides the $A$ subsample into those reporting that they "definitely will buy over the next twelve months or so," i.e., those answering yes to the $A_{1}$ intentions question, and those replying no. Similarly, the classification labeled $A_{1}$ or $A_{2}$ divides the A sample into those reporting either that they "definitely will buy over the next twelve months or so," or that they "probably or possibly will buy . . ." i.e., those answering yes to either the $A_{1}$ or $A_{2}$ intentions questions, and those not so reporting.

The seven dichotomous classifications are listed in order of the proportions of intenders typical for the thirteen commodities. These proportions are generally ordered in the same way for all of the commodities, although there are exceptions. A larger proportion of households reported intentions to buy food freezers when asked $A_{1}$ rather than $B_{1}$, for example, although the reverse is true for the other twelve items.

The first eight columns contain the raw data on purchases and buying intentions. Columns 1 and 2 show the number of purchasers, per hundred respondents, for the sample as a whole during the six months and twelve months, respectively, following the intentions survey. Column 3 shows the total number of intenders, again per hundred respondents, while columns 4 and 5 show the number of intenders who purchased within six and twelve months, respectively. Columns 6,7 , and 8 contain comparable data for nonintenders - total number per hundred, and of these, the number purchasing within six and twelve months.

The remaining eight columns contain statistics based on these data. Columns 9 and 10 show purchase rates among intenders and nonintenders, respectively, for the six-month period; columns 11 and 12 list the same statistic for the twelve-month period. Columns 13 and 14 show the pro-

- A few of the items listed on the survey schedule are not shown, either because they were purchased by so few households as to make the data behave erratically (house air-conditioning systems, home heating systems, color television sets) or because of doubt whether their classification as a "major" purchase was appropriate (movie camera). A good deal of evidence, both a priori and empirical, suggests that buying intentions have predictive value mainly with respect to relatively large-unit-cost items. 


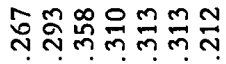

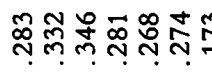

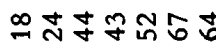

츠ำํำำำำ

n $N+\infty \forall$ In $N$

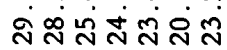

nTMm+r. مिं

$\infty$ Natr-0 in่

on- 0 a

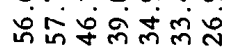

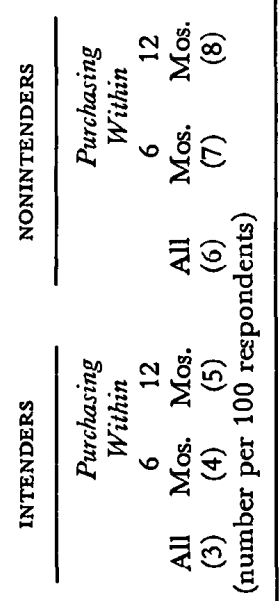

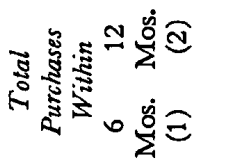

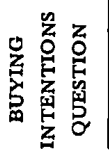

- N n $N$ -

งิ่ง

n o. ?mmo

$\forall m a \sigma^{\circ} \circ 0$

9 บ

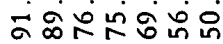

$\because \infty$ ก

ดั

UnN $\mathrm{N} \infty \mathrm{nm}$

षம0்

$\infty$ 엫ㅎㅁ

non-Tho

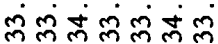
$\because \infty \emptyset+\infty \infty$ 형요용

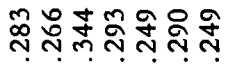

ஸึก ำ

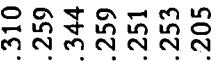

กิ่

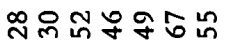

กับ

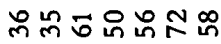

$\stackrel{\infty}{\infty}$

raOnaRT ON.

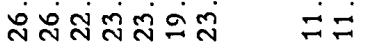

momaro to

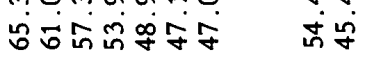

RONDONON
minก ํำ

里

m- naotr

ํํำ

is $0 \infty$ nn

Tr.mom $\mathrm{mm}$

ํํำํㅝㅁ

$a \infty$

응

o

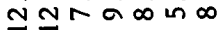

in $N$

in in

nn m m $\mathrm{m}$ N

$m m$

$\infty \dot{0}$

ปั

$\infty 6 a+b 0 a$

$\infty a \dot{0} \dot{0} \overline{2}$

$\rightarrow$ in

b 0 a n a m

bं $\dot{0} \dot{0} \dot{m}=$

웅

un m $n$ a $\infty$

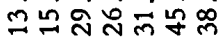

$n N$

in

$a m+\forall a+m$

ल

$\because m$ Nt noN $\infty \circ \dot{\circ} \dot{\circ} \dot{\circ}$

o $N$ in

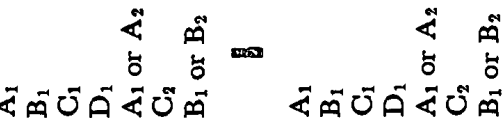
$\overline{4}$ 
BUYING INTENTIONS AND SUBSEQUENT PURCHASES

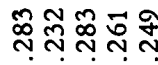

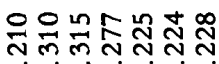

$\infty \infty \infty$

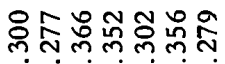

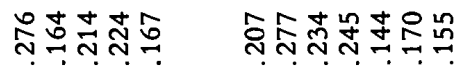

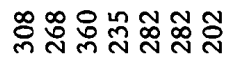

mก̊盘 $\mathrm{m}$

ㅇำ

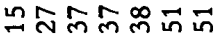

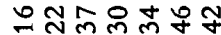

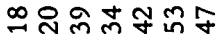

舟

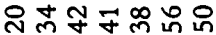

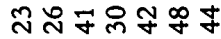

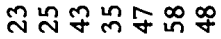

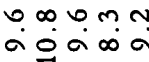

N In लं山 लं

N InONo $\dot{4}$ in

nn $\rightarrow \infty$ in ஸึ원

$N+0-\infty$ $\infty a \infty \cup 0$

$0, \pi \leadsto+$ $\dot{\forall} \dot{\forall} \dot{m} \dot{m}$

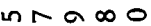
nீ

$\forall 0 \rightarrow$ un un isंir

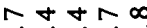
$\dot{N} \dot{m} \dot{m}$

n $m$ N NO

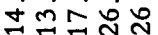

o $0 \mathrm{~m}$ $\dot{\sigma} \dot{\dot{g}} \dot{\square}$

nNGN ninin

¿ี ตี

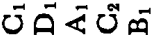

mก DNNA웅ㅇㅇㅇ

nNON

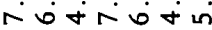

$\infty \infty m m$ n $\mathrm{n}$.

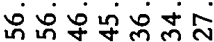
守 ํำ

toon 0 N

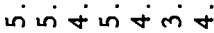

tom Lnton

ம்ர்む்m

$\infty 0$ in 0 in $0 \infty$ $=0 \infty a \infty 00$

NN naON

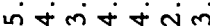

h.m. mont ผ

- $000 \mathrm{~m} \infty$ Nin in in

mmరt+ - NNMNm

matooa

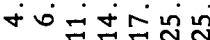

a o L N 0 แn $\Rightarrow m \dot{m} \dot{m} \dot{m}$ นn 0 r m n $\rightarrow 0$ ONDo
Tn $\mathrm{ln}$ m $\mathrm{mm}$

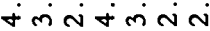

$\infty+\pi$ On 0 ₹

ก! แn $n 9$ i No 0 in m

$0+\operatorname{tn} 00 \rightarrow$ Ln $\dot{\nabla} \dot{\sim} \dot{\sim} \dot{N}$

n $\infty$ nn Nono

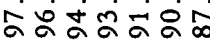

$+\infty$ in $\infty \rightarrow N 0$ $\therefore \sim \sim \sim m m m$

nNNTNOO $\rightarrow-\pi-N$ N

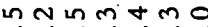
N

$\curvearrowleft+\infty$ o $\infty+$ $\infty \infty \dot{0} \dot{a} \dot{\infty} \infty$

NOHNMTO

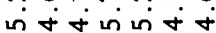

o- to 0 n N $N$ in

$0 \infty \mathrm{m} t$ n $0 m$ ㅇํำ

+anTm オmलmm

ma 유유 ํㅝㄴ manbarm ல

mol an a +miñN

nn+N+ba 人̊̊

约 -

$m m m a b-7$ n $m \cup \infty \cup \forall-$ Nming

mN ONMUN $\infty \infty \infty \infty \infty \infty$

$0-m+0 m-$ ก

$$
\text { ४ }
$$
ช

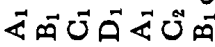


BUYING INTENTIONS AND SUBSEQUENT PURGHASES

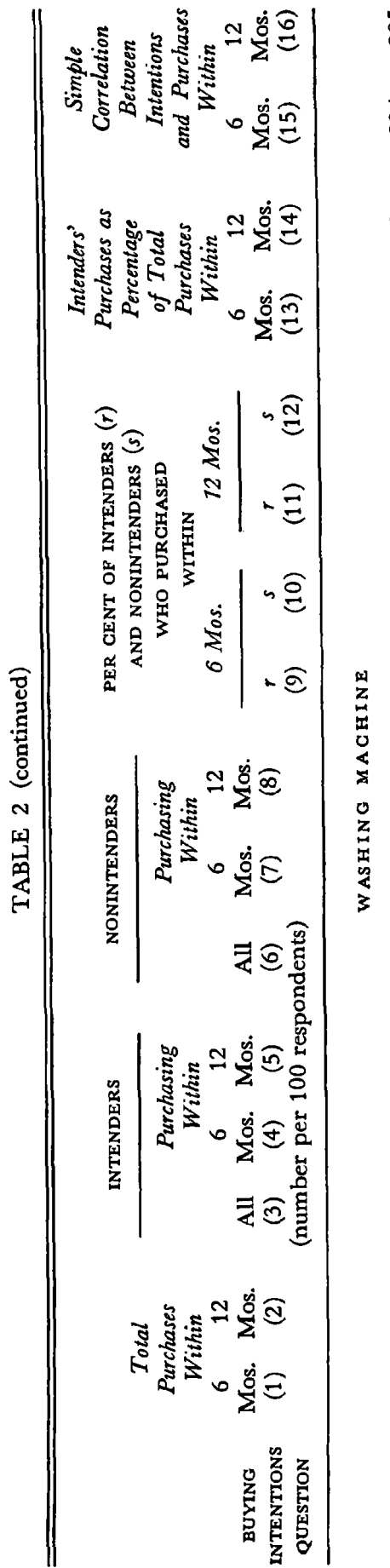

กำำกำ

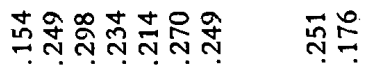

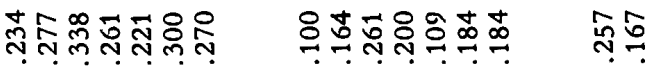

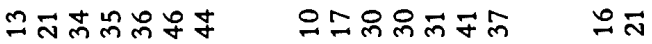

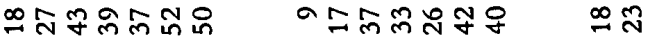

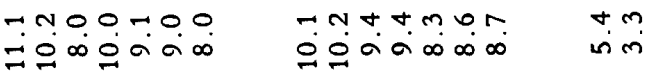

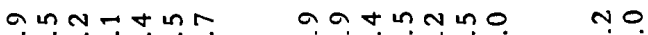

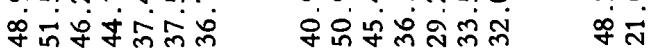

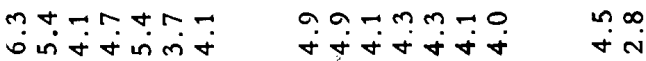

aninamino tinotiomin mo

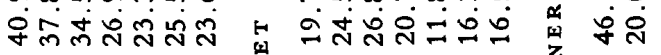

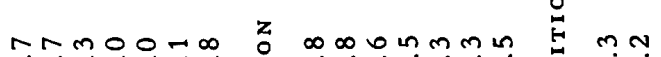

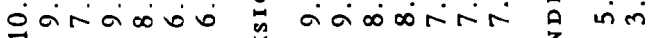

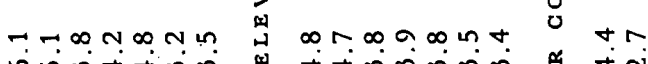

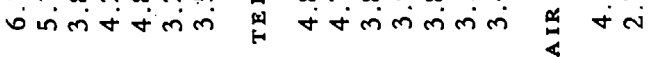

nom-7inm nagoton $g$ -

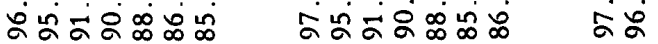

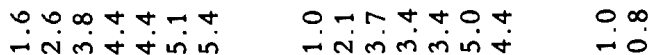

manrotin nongtam om

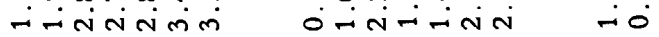

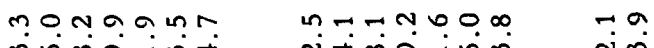

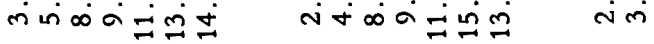

+n-a+Hn aamolama ma

Nㅗำำ

nobaino mnamman t Nibion lniminising in

की मี

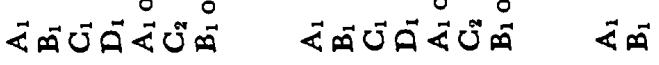




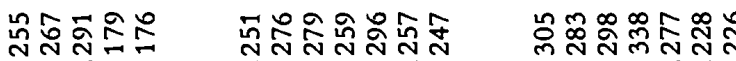

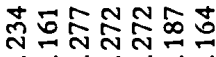

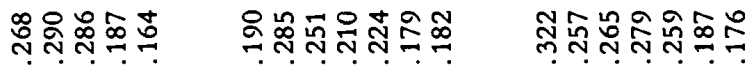

ํํㅇํํํํำํํำำ

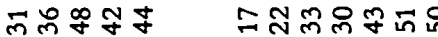

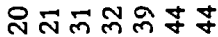

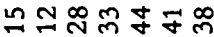

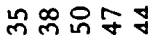

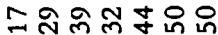

ลิงกำํํํ⿺ 丶

aNำ

Lก ON L

-

$\pi-H A m N N$

लिंलिं

من فำ in

サं்

$\operatorname{sentagh}$

लंषलिंत

$\operatorname{rn} 6 \mathrm{mt}$

$\operatorname{natman} 0$

antumn

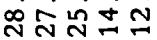

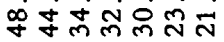

तi

n mONN $+\infty$

$\operatorname{noth}$

omanon m

an

Nminn

+minmin

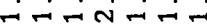

Noด $0 \infty \infty \infty$

$\infty \circ \circ \infty \infty$

AnnGNma

กักำำ

$\stackrel{\sim}{\sim} \cong \sim N$

$m+n R N$

$a a+m \infty a r$

miñ

0 in $\operatorname{cin}$ 的

o 0009

GONONN=

Nmin-

minल N N

N tamnN ตNํำㅇํㅇ

nanto

$n+r \infty 00 \infty$

丈

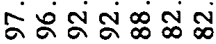

$00000+\infty$

$\forall \dot{\forall m m} \mathbf{N}$

arm $\operatorname{mm} m$

$\operatorname{ming}$

HTom mn

命

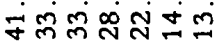

ก

naO Nom

लं

o-ra n no

mष்

Nom $n$ in

N

no요

ADNmLnN

oomáan

- imin-

$\therefore N \mathrm{Nm}$

- - - in

n. a n m

$\forall \infty n \infty$ in

$\infty N \infty+0, \pi=$

०00\%

$\therefore-\mathrm{N}-$

0ก-

a mo n $\ln \infty$

$m-\infty m o$

$\infty$ o

in $=\dot{+}$

Nin $=\infty$

- $\dot{4}+\dot{0}=$

anma

$\pi+c o-c \pi$

$0.0+90+0$

\& iों

$\infty N \infty+\infty N$

ก

$a \infty \forall a+$

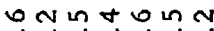

om n m o n

$\dot{m} \dot{\theta} \dot{m}$

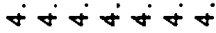

NกNMNN

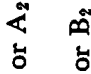

$\vec{U} \tilde{A}<\tilde{U}$
¿

岁占

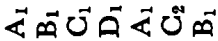

\&

ธั

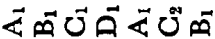

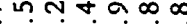

m

o trom n m -

$m \infty m+m m \infty$

$\dot{+} \dot{+} \dot{4} \dot{4} \dot{4}$

NonGRTo

กักกัก ก

+lomon

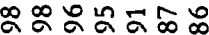

$$
\text { ๕ ค์ }
$$

เ

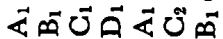




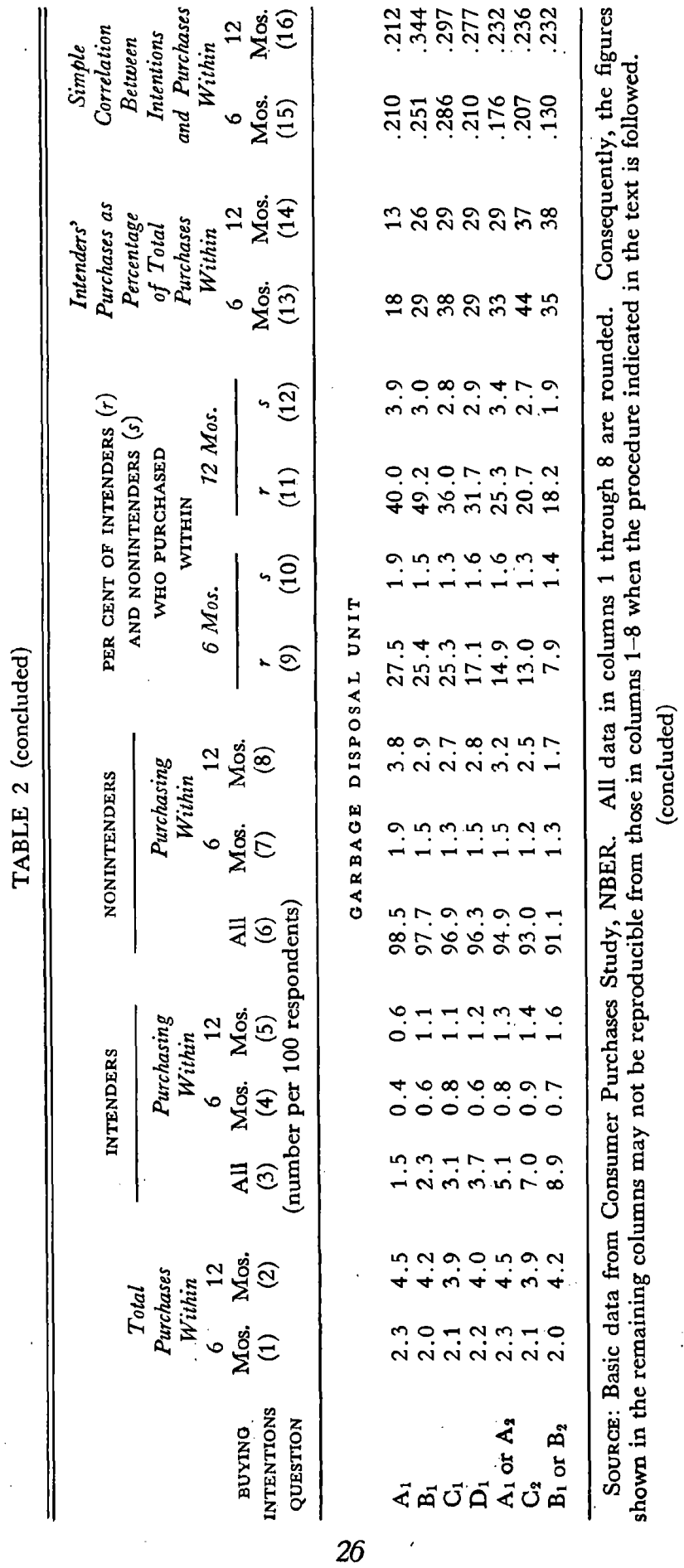


portion of total purchases accounted for by intenders during the six- and twelve-month periods, and the last two columns show the simple correlation between intentions and purchases for the respective purchase periods. In making the latter calculation, households were assigned values of unity or zero, depending on whether they reported intentions or purchases ( = unity) or did not do so (= zero).

It may be useful to spell out some of the definitional relations among these data. Column 1 is necessarily equal to the sum of columns 4 and 7, since total purchases must comprise purchases by intenders and nonintenders; similarly, column 2 is the sum of columns 5 and 8 . And columns 3 and 6 must always add to 100 , since they simply constitute different ways of breaking up the respective samples into intenders and nonintenders. The numbers of intenders and nonintenders who did not purchase within either six or twelve months after the survey (data not shown) are the respective differences (columns 3 minus 4 or 5) and (columns 6 minus 7 or 8 ).

The last eight columns are easily obtainable from the others. Column 9 is simply column 4 divided by column 3 , column 10 is 7 divided by 6 , column 11 is 5 divided by 3 , and column 12 is 8 divided by 6 . Purchase rates for intenders and nonintenders during the period from seven to twelve months after the survey can readily be calculated from the differences between columns 9 and 11 (intenders) or between 10 and 12 (nonintenders); the same figure can also be obtained by dividing column 3 into the difference between column 4 and 5 (intenders), or by dividing column 6 into the difference between 7 and 8 (nonintenders). Column 13 is simply column 4 divided by 1 , while column 14 is 5 divided by 2 . The derivation of the last two columns is not so obvious, but it can be shown ${ }^{7}$

${ }^{7}$ Following the terminology used by Okun (see Chapter 1), define:

$p_{i}$ as the proportion of the $i$ th sample reporting intentions to buy $\mathrm{A}$ at the beginning of the forecast period, where $i$ denotes a particular yes-no question about buying intentions and A denotes a particular commodity;

$x_{i}$ as the proportion of the $i$ th sample purchasing commodity A during the forecast period;

$r_{i}$ as the proportion of $i$ th sample intenders ("yes" responders) who purchase during the forecast period;

$s_{i}$ as the proportion of $i$ th sample nonintenders ("no" responders) who purchase during the forecast period.

In addition, let

$N_{i}$ denote the $i$ th sample size;

$P_{i}(1,0)$ denote a (yes, no) response to the $i$ th intentions question;

$X_{i}(1,0)$ denote a (yes, no) observation of purchase in the $i$ th sample.

Dropping the subscripts for convenience,

$$
R^{2} P, X=\frac{[\operatorname{Cov}(P, X)]^{2}}{\sigma^{2}{ }^{2} \sigma^{2} X}
$$


that column 15 must be equal to the square root of

$$
\left.\frac{\text { col. } 3(100-\operatorname{col} .3)}{\text { col. } 1(100-\operatorname{col} .1)} \text { times (col. } 9-\operatorname{col} .10\right)^{2}
$$

while column 16 must be equal to the same expression, substituting columns 2 for 1,11 for 9 , and 12 for $10 .^{8}$

But

$$
\operatorname{Cov}(P, X)=\frac{\sum_{1}^{n} P X}{N}-\overline{P X}
$$

Since $\bar{P}=p$, and $\bar{X}=x$, equations 1.0 can be written as

In addition,

$$
\begin{aligned}
\operatorname{Cov}(P, X) & =\frac{\sum_{1}^{n} P X}{N}-p x \\
& =p r-p x \\
& =p(r-x)
\end{aligned}
$$

$$
\sigma P^{2}=p(1-p)
$$

and

$$
\sigma_{X}^{2}=x(1-x)
$$

hence

By definition,

$$
R^{2} P, X=\frac{p^{2}(r-x)^{2}}{p(1-p) x(1-x)}
$$

$$
x=r(p)+s(1-p)
$$

Manipulating equation 5.0 to obtain an expression for $r-x$ and substituting into the numerator of equation 4.0 , we get

$$
R^{2}{ }_{P, X}=\frac{p^{2}(1-p)^{2}(r-s)^{2}}{p(1-p) x(1-x)}=\frac{p(1-p)(r-s)^{2}}{x(1-x)}
$$

which is the description given above in the text.

' The sign of the correlation coefficient is determined by the algebraic difference between intender and nonintender purchase rates, i.e., by column 9 minus column 10 . If these purchase rates are equal the correlation will be zero, a sensible enough result: for if nonintenders purchase with the same frequency as intenders, it obviously makes no difference whether households are classified as one or the other. In fact, column 9 always exceeds column 10; hence, all the correlations are positive.

In order for the correlation to be unity, it can be shown that column 9 must equal 100 per cent and column 10, zero per cent; that is, it must be true that all intenders purchase and that none of the nonintenders purchase. If this is the case, columns 3 and 1 must be equal, because intenders and purchasers are identical households, column 9 minus column 10 must equal unity, and the whole expression will equal unity.

Finally, if column 9 is less than unity, as is always the case, column 3 can never be 


\section{Analysis of Findings}

The empirical relations among these data exhibit some notable regularities. As I have pointed out, the classification by intentions question in the stub of Table 2 has been ordered so that the proportion of intenders (column 3) increases steadily as it is read from top to bottom. The pattern is not perfectly consistent for all thirteen commodities, but deviations appear only when two adjacent classifications have approximately equal proportions of intenders in any case. Columns 1 and 2 should be random with respect to the different subsamples and intentions questions, since both represent purchase rates for the group as a whole and the subsamples were selected by a random process. The data in these columns clearly follow the expected random pattern; for example, automobile purchase rates among the seven subgroups of households asked alternative intentions questions vary only from 33.0 per cent $\left(\mathrm{B}_{1}\right)$ to 34.7 per cent $\left(\mathrm{C}_{1}\right) .{ }^{9}$

Although total purchases show only random variation among the seven subgroups, both the number and proportion of intenders and nonintenders who purchase any given commodity are systematically related to the proportion of intenders: the larger the proportion of intenders in the sample-column 3-the greater the number of purchases made by intenders-columns 4 and 5-but the smaller the proportion of intenders who purchase-columns 9 and 11. Correspondingly, the smaller the proportion of nonintenders - column 6 - the fewer the number of purchases by nonintenders-columns 7 and 8 ; but in contrast to the pattern for intenders, the smaller the proportion of nonintenders in the sample the smaller the proportion of nonintenders who purchase-columns 10 and 12. It follows that the proportion of total purchases accounted for by intenders-columns 13 and 14-is higher the larger the proportion of intenders in the sample. ${ }^{10}$ Finally, the purchase rate of intenders is always

enough higher than column 1 to make the whole expression equal unity. At the extreme, assume that column $9(=r)$ is less than unity but that column $10(=s)$ is still zero; that is, all purchases are still made by intenders, but some intenders do not purchase. In that case it can be shown that the correlation between $P$ and $X$ is equal to the square root of $\frac{(r-x)}{(1-x)}$, which must be less than unity if $r$ is less than unity. In fact, all the correlations are quite small, as is to be expected with cross-section data of this kind.

9 Purchase rates among the seven subgroups differ significantly (0.05 level) from each other in only two of twenty-six possible comparisons.

${ }_{10}$ To illustrate: perthous and households in the $A_{1}$ sample, 191 and 332 purchased an automobile within six and twelve months, respectively; only 81 reported intentions to buy an automobile. Of the 81 intenders, 45 purchased within six months, 61 within twelve months. Thus, almost 57 per cent of the $A_{1}$ intenders bought within 
higher than that of nonintenders, given the commodity, for any of the intentions questions and in either of the two purchase periods, as well as in any part of these periods. ${ }^{11}$

The above generalizations apply equally well to both six- and twelvemonth purchase periods and can be observed in the data for all thirteen commodities tested, although data for a few products behave erratically (air conditioners and television sets in particular). The consistency of these relationships is indicated by Table 3, which shows rank correlations between the proportion of intenders in the sample and each of the relevant columns. Ranks are used rather than absolute values because the relationships are generally nonlinear, as discussed at greater length in Chapter 3 .

These relations have a tendency to be somewhat more consistent for the twelve-month purchase period than for the shorter period. The reason may simply be that absolute differences among the groups tend to be greater for the longer period; hence, the ranks for six months' purchases may be affected by purely sampling variability to a somewhat greater degree. However, the strength of these relations apparently is not determined by any particular characteristic of the commodities examined. The thirteen items include those with very high unit cost (automobiles) and much lower unit cost (garbage disposal units); they include items with very high ownership ratios (auto, range, refrigerator) and very low ownership ratios (dishwasher, food freezer, air conditioner). Yet the rank correlations and a careful inspection of the basic data themselves fail to show that either of these characteristics is associated with systematically

six months, while about 75 per cent bought within twelve months. And of the 919 $A_{1}$ nonintenders per thousand households, 145 bought within six months and 271 within twelve months, amounting to roughly 16 and 30 per cent, respectively, of the $A_{1}$ nonintenders. Finally, 45 of the 191 households (per thousand) in $A_{1}$ who purchased an automobile within six months were intenders (about 24 per cent), while only 61 of 332 purchases within twelve months (roughly 18 per cent) were made by intenders. In contrast, per thousand $\left(B_{1}\right.$ or $\left.B_{2}\right)$ households, 494 reported intentions to buy an automobile, although about the same number as in $A_{1}$ actually purchased within either six or twelve months-198 and 330, respectively. Of the 494 intenders, 133 bought within six months, 213 within twelve months; thus 27 and 43 per cent, respectively, of the $\left(B_{1}\right.$ or $\left.B_{2}\right)$ intenders purchased within six and twelve months. And of the 506 nonintenders in this group, 66 and 117 purchased within six and twelve months, respectively, amounting to 13 and 23 per cent. Finally, 133 of the $198\left(B_{1}\right.$ or $\left.B_{2}\right)$ households (per thousand) who purchased automobiles within six months were intenders, as were 213 of the 330 who purchased within a year; these correspond to about 67 and 64 per cent, respectively. (Details may not add to totals due to rounding.)

11 Data for the period from seven to twelve months after the survey can be obtained by simply subtracting six-month from twelve-month data in all but the last four columns (13 through 16) of Table 2. 
TABLE 3

Rank Correlations Between Intenders and Purchasers, by Commodity

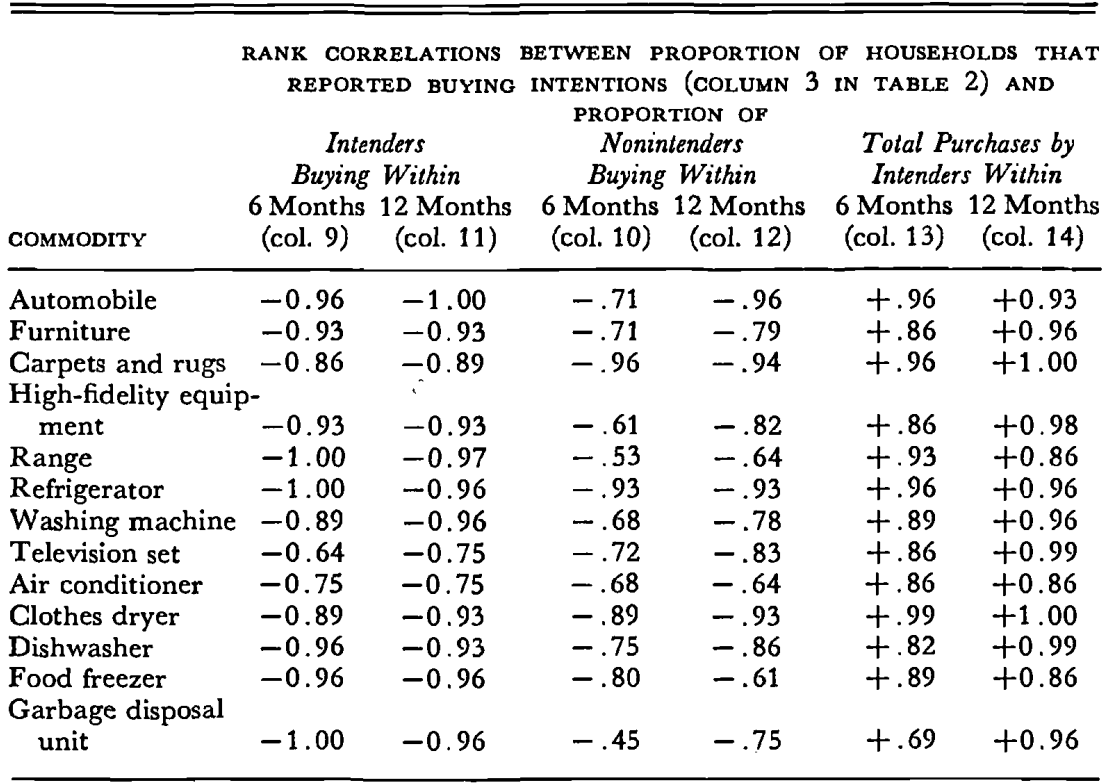

Source: Estimated from basic data in Table 2.

Note: Correlation coefficients higher than 0.86 are statistically significant at the 0.01 level; those higher than 0.74 are significantly different from zero at the 0.05 level.

weaker or stronger relationships between the proportion of intenders and the other variables.

There are, of course, systematic differences in the data that do relate to characteristics of the commodities. For example, items owned by most of the sample generally tend to have higher purchase rates, not only in the sample as a whole, which is to be expected, but among both intenders and nonintenders for any given intentions question. Items like automobiles, furniture, and refrigerators tend to have six-month purchase rates among intenders that range from upward of 40 per cent down to roughly 25 per cent, depending on the intentions question; for the twelve-month period, purchase rates for these kinds of items range from upward of 60 per cent down to roughly 35 per cent. For commodities with low ownership ratios, in contrast, purchase rates for intenders rarely exceed 30 per cent for the six-month period and occasionally drop to as low as 10 per cent, again depending on the intentions question; for the twelve-month period, purchase rates for these items rarely exceed 45 per cent and frequently go down to 20 per cent or lower. The same pattern is apparent in the pur- 
chase rates of nonintenders for commodities with differing ownership ratios, except that the contrast is even sharper.

In addition, the data show clearly that, among commodities for a given intentions question, purchase rates for both intenders and nonintenders tend to be correlated with purchase rates for the sample as a whole; this is hardly surprising, since purchase rates for the sample must be a weighted average of those for intenders and nonintenders. But the correlation is typically much stronger for nonintenders than for intenders, and the difference cannot be attributed to the fact that nonintenders make most of the purchases. This would explain why the purchase rates of $A_{1}$ or $B_{1}$

TABLE 4

Rank Correlations Between Sample Purchase Rates for Thirteen Commodities and Purchase Rates of Intenders and Nonintenders

\begin{tabular}{|c|c|c|c|c|c|c|}
\hline \multirow[b]{3}{*}{$\begin{array}{c}\text { INTENTIONS } \\
\text { QUESTION }\end{array}$} & \multicolumn{4}{|c|}{$\begin{array}{l}\text { RANK CORRELATION COEFFICIENT BETWEEN } \\
\text { SAMPLE PURCHASE RATES AND THOSE FOR }\end{array}$} & \multirow{2}{*}{\multicolumn{2}{|c|}{$\begin{array}{c}\text { Median Per Cent } \\
\text { of Purchases } \\
\text { Made by Intenders } \\
\text { Within }\end{array}$}} \\
\hline & \multicolumn{2}{|c|}{$\begin{array}{l}\text { Intenders } \\
\text { Purchasing Within }\end{array}$} & \multicolumn{2}{|c|}{$\begin{array}{c}\text { Nonintenders } \\
\text { Purchasing Within }\end{array}$} & & \\
\hline & $\begin{array}{l}6 \text { Months } \\
\text { (1) }\end{array}$ & $\begin{array}{l}12 \text { Months } \\
\text { (2) }\end{array}$ & $\begin{array}{l}6 \text { Months } \\
\text { (3) }\end{array}$ & $\begin{array}{l}12 \text { Months } \\
\text { (4) }\end{array}$ & $\begin{array}{l}6 \text { Months } \\
\text { (5) }\end{array}$ & $\begin{array}{c}12 \text { Months } \\
\text { (6) }\end{array}$ \\
\hline$A_{1}$ & .57 & .63 & 0.97 & 0.99 & 20 & 16 \\
\hline$B_{1}$ & .59 & .74 & 1.00 & 0.99 & 27 & 22 \\
\hline $\mathrm{C}_{1}$ & .30 & .71 & 0.98 & 0.99 & 41 & 34 \\
\hline$D_{1}$ & .61 & .71 & 1.00 & 1.00 & 35 & 33 \\
\hline$A_{1}$ or $A_{2}$ & .58 & .88 & 0.94 & 0.98 & 45 & 42 \\
\hline $\mathrm{C}_{2}$ & .86 & .90 & 0.98 & 0.98 & 50 & 46 \\
\hline $\mathrm{B}_{1}$ or $\mathrm{B}_{2}$ & .78 & .75 & 0.97 & 0.97 & 48 & 44 \\
\hline
\end{tabular}

Source: Estimated from basic data in Table 2.

nonintenders are more closely related to sample purchase rates than those of $A_{1}$ or $B_{1}$ intenders; in both cases nonintenders typically account for more than three-fourths of total purchases and comprise over four-fifths of all households. Thus, differences in sample purchase rates (among commodities) must show up as roughly equivalent differences in nonintender purchase rates. But for the $\mathrm{C}_{2}$ and the $\left(\mathrm{B}_{1}\right.$ or $\left.\mathrm{B}_{2}\right)$ intentions questions, the association between nonintender and sample purchase rates is also much closer than that between intender and sample rates, even though intenders typically account for about half of total purchases. This relationship can be seen (Table 4) from the rank correlations, for each of the seven intentions questions, between sample and both intender and nonintender purchase rates.

All of the relationships described above are consistent with the proposi- 
tion that responses to questions about buying intentions are essentially a reflection of the respondents' subjective probability of purchase for particular products. The more restrictive the phrasing of a question about buying intentions, either because the specified time period is relatively short or because certainty specifications are explicitly stated in the question, the higher must be the respondent's purchase probability for a yes answer to be forthcoming. Similarly, the less restrictive the phrasing of the question, the lower the purchase probability that might be associated with yes responses. This hypothesis is elaborated and tested in Chapter 3. For present purposes, it is sufficient to note that the probability interpretation suggests one of the criteria for optimality in a buying-intentions question: any household reporting that it "intends to buy" should have a higher subjective purchase probability than a household" reporting that it "does not intend to buy." In effect, an optimal intentions question should at least eliminate overlap or misclassification, in that every intender should have a higher purchase probability than every nonintender. ${ }^{12}$

\section{The Efficiency of Alternative Intentions Questions}

In the remainder of this chapter, alternative intentions questions are examined with a view to determining which is the best predictor of subsequent behavior. The last two columns of Table 2 showed the simple correlation between responses to the alternative intentions questions and purchases during six- and twelve-month periods after the survey. For prediction, it is clear that the best intentions question is simply the one which has the highest correlation with subsequent purchases.

It is worth noting that the intentions question that best predicts future purchases is not necessarily more efficient than the available alternatives in the sense that there must be less misclassification between intenders and nonintenders with respect to purchase probabilities. An intentions question for which every intender has a higher purchase probability than every nonintender can be a much poorer predictor of future purchases, using the maximum-correlation criterion, than an alternative question for which some intenders had lower probabilities than some nonintenders. The latter question may identify many more prospective purchasers than the former; and the variation in purchases is what needs to be explained. For example, in the illustration below the two households reporting intentions on question 1 very likely have higher subjective probabilities of purchase

\footnotetext{
12 It does not follow that observed purchase rates are bound to be higher for intenders than for nonintenders in every conceivable group of households: unforeseen events influence (ex post) purchases but not (ex ante) purchase probability.
} 
than any of the 98 nonintenders, while it is perfectly possible that at least some of the 40 question-2 intenders have lower probabilities than some of the 60 nonintenders. ${ }^{13}$ Of course a question that is similar to 2 but

\begin{tabular}{crrr} 
& \multicolumn{4}{c}{ QUESTION 1} \\
Intentions & \multicolumn{3}{c}{ Purchases } \\
to Buy & Yes & No & Total \\
Yes & 2 & 0 & 2 \\
No & 18 & 80 & 98 \\
Total & 20 & 80 & 100 \\
& $r_{P, x}$ & .29 &
\end{tabular}

\begin{tabular}{cccc}
\multicolumn{4}{c}{ Question 2} \\
Intentions & \multicolumn{4}{c}{ Purchases } \\
to Buy & Yes & No & Total \\
Yes & 15 & 25 & 40 \\
No & 5 & 55 & 60 \\
Total & 20 & 80 & 100 \\
& \multicolumn{3}{c}{.36}
\end{tabular}

which successfully reclassifies households - so that every intender has a higher purchase probability than every nonintender-will predict even better than 2; but that may not be an available alternative. As the illustration suggests, the proportion of intenders in the sample is relevant to the question of predictive accuracy.

The data in Table 2 (columns 15 and 16) indicate that all of the observed correlations-between any of the intentions variables and purchases of any commodity-are positive, although all are relatively small in absolute terms; none of the observed correlations exceeds 0.40. As noted above and elaborated in Chapter 3, this is to be expected.

Using the maximum-correlation criterion it is evident that, among the alternatives shown in Table 2, intentions question $C_{1}$ is noticeably better than any of the others. $\mathrm{C}_{1}$ shows the highest correlation of any intentions question with purchases (six-month period) for seven of the thirteen commodities, and the second highest for three others; for purchases during the twelve-month period, $\mathrm{C}_{1}$ shows the highest correlation in eight cases, and the second highest in three of the remaining five. No other intentions question is even remotely as good a predictor, as shown in Table 5: if a question had the highest correlation among all seven questions for each of the thirteen items, its average rank would be 1.0; if the lowest correlation for all items, the average rank would be 7.0. The average proportion of the variance in purchases explained by each of the intentions questions is also shown; this average is taken as the median squared correlation among the thirteen commodities.

Several points should be noted. First, of the intentions questions currently used by the major consumer surveys $\left(A_{1}, A_{2}, B_{1}, D_{1}\right)$ there is rela-

13 The reader will recall that the squared correlation coefficient between buying intentions and purchases is equal to:

$$
(r-s)^{2} \frac{p(1-p)}{x(1-x)}
$$

where the variables are as defined earlier. 
TABLE 5

Average Ranking and Proportion of Explained Variance in Purchases, ThIR TEEN COMMODITIES

\begin{tabular}{|c|c|c|c|c|}
\hline \multirow{2}{*}{$\begin{array}{l}\text { Intentions } \\
\text { Questions }\end{array}$} & \multicolumn{2}{|c|}{$\begin{array}{l}\text { Purchases Within } \\
\text { Six Months }\end{array}$} & \multicolumn{2}{|c|}{$\begin{array}{c}\text { Purchases Within } \\
\text { Twelve Months }\end{array}$} \\
\hline & Mean Rank & Median $r^{2}$ & Mean Rank & Median $r^{2}$ \\
\hline$A_{1}$ & 3.2 & .066 & 5.1 & .063 \\
\hline$B_{1}$ & 3.8 & .067 & 4.5 & .076 \\
\hline $\mathrm{C}_{1}$ & 1.8 & .072 & 1.6 & .089 \\
\hline$D_{1}$ & 3.6 & .060 & 3.4 & .077 \\
\hline$A_{1}$ or $A_{2}$ & 4.8 & .050 & 4.0 & .077 \\
\hline & 4.4 & .043 & 3.7 & .068 \\
\hline$B_{1}$ or $B_{2}$ & 6.3 & .031 & 5.8 & .061 \\
\hline
\end{tabular}

SOURce: Estimated from basic data in Table 2.

tively little difference in predictive performance. For predicting purchases six months ahead, $A_{1}$ (definitely intend to buy within a year) and $B_{1}$ (plan to buy within six months) are slightly superior to $D_{1}$ or to the combination of $A_{1}$ and $A_{2}$. But for predicting purchases twelve months in advance, $A_{1}$ is clearly the worst of the three; and there is little to choose among $B_{1}, D_{1}$, or the $A_{1}, A_{2}$ combination. ${ }^{14}$ The $C_{1}$ question is significantly better than any of these for predicting purchases either six or twelve months ahead. Although the differences in explained variance are small in absolute terms, the correlation between purchases and $\mathrm{C}_{1}$ intentions is significantly higher in 51 of 104 cases- 0.05 probability level-than the

14 The phrase "for predicting purchases six or twelve months in advance" refers to the prediction of differences in behavior among households during the respective periods. That is to say, the preceding correlations measure the degree of accuracy with which the incidence of future purchase or nonpurchase among a group of households is predicted by one question or another. It does not follow that predictions about change in population purchase rates over time must necessarily be more accurately foreshadowed by the question that best distinguishes differences among households, but it is quite likely that this is the case. If the cross-section correlation between intentions question $A$ and purchases is higher than that between question $B$ and purchases, and if the time series variance in the proportion of $\mathrm{A}$ intenders in the population is at least as high as that of $B$ intenders, the time series correlation between the proportion of $\mathrm{A}$ intenders and purchases must exceed that between the proportion of $\mathrm{B}$ intenders and purchases; if the time series variance in the proportion of $A$ intenders is lower than that of $B$, the time series correlation between $A$ and purchases may not be higher than that of $B$ and purchases (see Chapter 3, where this relation is discussed).

To the extent that data are available, they indicate that the intentions questions that show (above) relatively high cross-section correlations tend to have relatively high time series variances in the proportion of intenders as well. This statement would certainly apply to a comparison among $A_{1}, A_{1}$ or $A_{2}, B_{1}, C_{1}$, and $D_{1} ; A_{1}$ and $B_{1}$ tend to have cross-section correlations that are lower or about the same as the others, and both are known to have a smaller time series variance than $\left(A_{1}, A_{2}\right)$ or $D_{1}$. No time series data on $C_{1}$ are available, but the time series variance of $C_{1}$ would presumably be much like that of $D_{1}$. 
correlation between purchases and other intentions questions. ${ }^{15}$ In only one of 104 cases is the $\mathrm{C}_{1}$ correlation significantly lower. Further, although the differences in explained variance seem small, an $r^{2}$ of 0.08 does represent an improvement of 33 per cent over an $r^{2}$ of 0.06 . If this can be translated into an improvement in the accuracy of time series predictions, the gain is far from small.

Next, the time dimension specified in the intentions question seems to have no bearing at all on the purchase period for which any given question is most useful as a predictor. As noted, the $A_{1}$ question is almost identical to $B_{1}$ for predicting six months ahead, but worse than $B_{1}$ for predicting

TABLE 6

Accuracy of Prediction of Intentions Questions, Six Months and Twelve Months Forward

(number of commodities for which $r_{P, X}$ is higher)

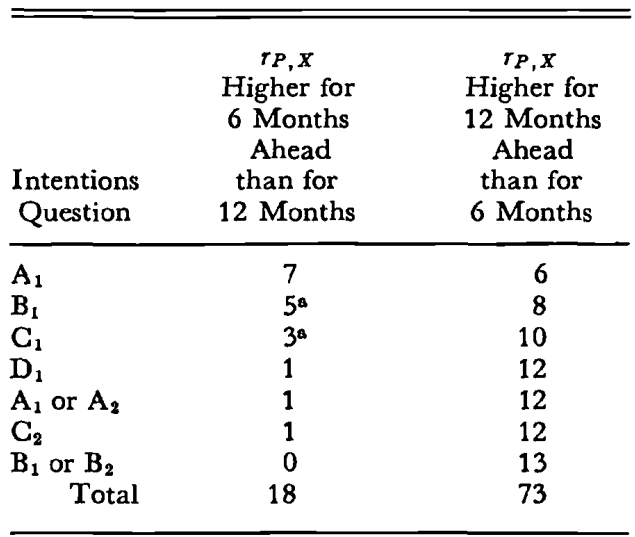

Source: Estimated from basic data in Table 2.

a Six-month and twelve-month correlations were equal in one of these cases.

twelve months ahead. Yet $A_{1}$ asks about prospective purchases over a twelve-month period, $B_{1}$ about prospective purchases over a six-month period! In fact, the relation that stands out here has to do solely with the proportion of intenders associated with a particular question. The data (Table 6) indicate that the smaller the proportion of intenders (because the question asks about purchases for a relatively short time period, or specifies a high degree of certainty, or does both), the better the question predicts six months ahead and the worse it predicts twelve months ahead. Further, it is interesting to note that all of the intentions questions on the CU survey, with the single exception of $A_{1}$, tend to predict more accurately for a twelve months' forward period than for six months ahead. Although

15 The 104 cases consist of four comparisons $-C_{1}$ with, respectively, $A_{1}, A_{1}$ or $A_{2}, B_{1 \text { s }}$ and $D_{1}$-for each of thirteen commodities in each of two time periods. 
the twelve-month correlations are generally higher than the six-month ones it does not follow, of course, that the correlation between intentions and purchases is higher for the "second" six months-the period from seven to twelve months after the survey-than for the first six months. The correlation between intentions reported at the survey date and purchases during the second six months, while always positive, is higher than the first-six-months correlation in only five of ninety-one cases; but combining the first and second six-month periods generally seems (empirically) to yield better cross-section predictions than those observed for the sixmonth period immediately following the intentions survey. ${ }^{16}$

There also appear to be some differences in the relative predictive accuracy of these questions with respect to type of commodity, especially for twelve-month predictions. Excluding automobiles, which comprise a unique category, the remaining items can be divided into groups characterized by relatively high or low ownership ratios. ${ }^{17}$ Although the $\mathrm{C}_{1}$ intentions question predicts both categories more accurately than any other question during both purchase periods, it predicts twelve-month purchases of items with high ownership ratios much more accurately than the other questions but has only a small advantage over $D_{1}$ or $\left(A_{1}, A_{2}\right)$ for predicting twelve months' purchases of items in the low-ownership group. ${ }^{18}$ And the question next best to $\mathrm{C}_{1}$ for predicting purchases of high-ownership items is $\mathrm{C}_{2}$, which is basically $\mathrm{C}_{1}$ plus an additional question (see Table 1).

${ }^{16}$ Even though purchases during the second six-month period are positively correlated with buying intentions reported at the survey date, it need not follow that predictions for twelve months ahead are better than those for six months ahead. To the degree that intenders buy during the second six months, the twelve-months-ahead correlations will be higher than the six-month ones; but to the degree that nonintenders buy during the second six months, the twelve-month correlations will be lower. It happens that the first of these factors generally outweighs the second.

Further, it does not necessarily follow that predictions about change in purchase rates over time must also be better for a twelve-month forecast period than for six months ahead, given the fact that cross-section predictions are better for the longer period. This would be the case only if (1) no unforeseen events took place at all, or (2) those unforeseen events with time series variance had the same or a lesser variance when averaged over twelve-month periods than over six-month ones.

${ }^{17}$ Air conditioners, clothes dryers, dishwashers, food freezers, garbage disposal units, and high-fidelity equipment are regarded as low-ownership items; carpets and rugs, furniture, ranges, refrigerators, television sets, and washing machines are designated as the high-ownership group.

${ }^{18}$ For the six items in the high-ownership category, $\mathrm{C}_{1}$ explains from 8.0 to 14.3 per cent of the variance in twelve-months purchases; the average for the six is 11.2 per cent. The next best question, aside from $C_{2}$, is $D_{1}$, which explains from 5.4 to 12.4 per cent of the variance in twelve-month purchases, averaging 8.6 per cent. Thus $\mathrm{C}_{1}$ is almost 30 per cent better than its closest competitor in this particular category. $C_{1}$ is also substantially more accurate in predicting automobile purchase twelve months ahead, being about 30 per cent better than its closest competitor. 
Finally, it is easily shown that not only is $\mathrm{C}_{1}$ a more efficient intentions question in that it consistently shows higher correlations than the alternative questions, but it is also more efficient in the sense of having a lesser degree of overlap or misclassification, given the subjective purchase probabilities of intenders and nonintenders. I have already noted that the question with the highest cross-section correlation need not necessarily have the least overlap if the proportions of intenders and nonintenders are quite different among the questions. If the proportions are the same, however, maximum correlation implies minimum misclassification; in fact, differences in correlation are entirely due to differences in the extent of misclassification..$^{19}$ If the proportions of intenders for the alternative questions are even roughly the same, as is clearly the case here, it can be shown that differences in the correlation coefficients, assuming the complete absence of misclassification, will tend to be smaller than those observed between $\mathrm{C}_{1}$ and the other intentions questions. ${ }^{20}$ Hence, the observed differences in the correlations of purchases with $\mathrm{C}_{1}$ and purchases with the alternative intentions questions must be due in some part to the fact that

10 If, among households asked intentions question $\mathrm{A}, 10$ per cent report intentions, and if an identical proportion of households report intentions for question B, any difference in the correlation between purchases and $A$ intentions or purchases and $B$ intentions must be due entirely to differences in the observed purchase rates of intenders and nonintenders. In note $7, \mathrm{I}$ developed the proposition that the correlation between intentions $(P)$ and purchases $(X)$ can be expressed as

$$
r^{2} P_{i}, x_{i}=p_{i}\left(1-p_{i}\right)\left(r_{i}-s_{i}\right)^{2} / x_{i}\left(1-x_{i}\right),
$$

where the subscript refers to the $i$ th sample. If both the $i$ th sample (those asked intentions question $\mathrm{A}$ ) and the $j$ th sample (those asked intentions question $\mathrm{B}$ ) show the same proportion of intenders, then $p_{i}=p_{j}$. Neglecting sampling errors and assuming that $i$ and $j$ are both random samples, $x_{i}=x_{j}$. Thus, if $r^{2}\left(P_{1} X\right)_{i}$ and $r^{2}(P . X)_{i}$ differ, it must be that $r_{i}-s_{i}$ and $r_{j}-s_{j}$ are not equal; the sample with the larger such magnitude will have the higher correlation. But the $r$ and $s$ quantities are simply the purchase rates for intenders and nonintenders, respectively. If these purchase rates are closer together in one sample than in the other, it must be because the mean purchase probabilities of intenders and nonintenders are also closer together; hence, one question must misclassify to a greater extent than the other.

20 An illustrative tabulation, which assumes that households have specified purchase probabilities, that they purchase in accord with the average of these probabilities, and that they answer an array of intentions questions with either yes or no depending on their purchase probability and on the characteristics of the question, yields the following results (for each intentions question, it is assumed that every intender has a higher purchase probability than every nonintender; that is, each intentions question splits the sample cleanly between high- and low-probability households; hence, there is no misclassification at all): Squared correlation between intentions and purchases

$\begin{array}{lllllll}.045 & .065 & .096 & .03 & .106 & .101 & .074\end{array}$

Note that the correlation falls off very sharply when there are very few or very many intenders relative to the number of purchasers-the mean purchase rate in the above illustration was assumed to be 18.7 per cent, roughly the observed six months' purchase rate for automobiles in the GU data. But in the range from $p=0.04$ to 
$\mathrm{C}_{1}$ misclassifies households to a lesser extent than do the alternative questions.

The findings just discussed have some obvious implications for survey design. These are discussed at length in Chapter 3, which is mainly concerned with the probability interpretation of buying intentions questions. At this point, the reader should note again one rather striking fact. Of the alternative dichotomous (yes-no) questions about buying intentions for specific commodities, one variant- $\mathrm{C}_{1}$-consistently predicts better than any of the others. The structure of this variant is rather interesting. ${ }^{21}$ Respondents were asked three questions about intentions to buy a list of durables: (1) "Which . . . do you plan to buy . . . ? (2) Which would you buy . . . if your family income were to be 10-15 per cent higher than you now expect?"; and (3) "Which . . . would you buy . . . if your income were ... lower than you now expect?" The second of these questions implicitly includes the first, in that respondents would presumably report a greater amount of prospective expenditure (though not necessarily the same items plus some additional ones) if their income were to be higher than expected than if it were not. And the entire set of questions clearly imply that responses to the first question should be contingent on the family income behaving about as currently anticipated, since replies to the other two questions are specifically contingent on the assumption that income diverges from current expectations.

This set of questions has two aspects that set it apart from the others. First, the questions are extremely cumbersome, especially for a mail questionnaire. In trying to design a reasonably compact format, I finally decided to include, along with the list of commodities, nothing but the box head

$$
\frac{\text { Plan to Buy }}{\text { A B C }}
$$

This was the only description directly above the columns in which checkmarks were to be made. The reader was asked to "please fill in all three columns after reading questions $\mathrm{A}, \mathrm{B}$, and $\mathrm{C}$ above." It was hoped that respondents would thus be forced to read all three questions carefully,

$p=0.20$, differences among the correlations are relatively small despite the sizable variation in the proportion of intenders.

Another illustrative calculation based on similar assumptions but with a lower purchase rate assumed for the sample-one of 8 per cent-indicates that the correlations fall off very sharply when the proportion of intenders goes below 0.02 or rises above 0.10 . These calculations are basically arbitrary, of course,"-but the general principle seems valid.

21 I am pleased to record my debt to Ruth P. Mack, who suggested the question and persuaded me that it constituted an interesting gamble. 
and hence be forced to decide before answering any of the questions whether to classify prospective purchases as being contingent on unusually favorable income developments or, more importantly perhaps, not being so contingent. In effect, a reasonably specific set of guidelines were provided as to the meaning of the words "plan to buy"; in the context of the format used on the $\mathrm{C}$ questionnaire, a plan to buy should have been construed as a purchase that would be made if everything were to work out neither more nor less favorably than anticipated. But using the appropriate guidelines must have required a fair amount of thought by the respondent, and could not have represented a "top of the head" reaction to a question about prospective purchases.

Secondly, the question encouraged respondents to think about prospective purchases in terms of contingencies and probabilities. After all, respondents cannot rationally say what they would buy "if income were to be higher than [they] now expect" until they first decide what they expect income to be. And I would think it plausible that many respondents were encouraged to make judgments about contingencies other than family income in answering the question, since the phrasing clearly implies that contingencies as a class of events should be reflected in responses. For example, I would suppose that respondents to the $\mathrm{C}$ questionnaire gave more attention than other respondents to the condition of their durables stock before deciding about purchase intentions. The phrase "what would you buy if income were to be higher than you now expect" suggests that responses to intentions questions should also depend on what would be done if, e.g., a major repair bill came along on the family car, thus leading to a greater awareness that the probability of a major repair bill is a relevant consideration in deciding whether or not to report carbuying intentions.

Since the $\mathrm{C}_{1}$ intentions question shows markedly better predictions, I infer that survey respondents should be asked questions that explicitly suggest the complicated nature of a probability judgment, rather than questions with undefined phrases that the respondent must interpret as best he can. Further, I infer that buying intentions questions should be asked after the respondent has been questioned about his financial situation, expectations, durables stock position, and so forth, since any realistic judgment about purchase probability clearly must depend on such considerations.

\section{Comparisons with Random Population Samples}

It may be objected that the superior predictive performance of the $\mathrm{C}_{1}$ question in these cross sections, and the inferences drawn, mainly reflect 
special characteristics of a sample of Consumers Union subscribers and, hence, are not relevant to surveys of a representative sample of the population. There is no way, given the data now available, to evaluate this possibility directly. All of the indirect evidence that I have seen suggests that households in the CU sample are no different from a random selection of all households except for measurable differences in financial, demographic, and educational status-households in the CU sample are known to be considerably richer, somewhat younger, and much more highly educated than the population at large. But the data also indicate that household characteristics like these either are unrelated to purchase rates among intenders and nonintenders for the alternative intentions questions, or are systematically related in the same way for all the questions. Thus, differences in the predictive performance of the intentions question do not seem related in any way to financial, demographic, or educational factors. Further, the above data contain several intentions questions that are essentially identical to those asked of random population samples. The observed purchase rates for intenders and nonintenders in the CU data, given comparable intentions questions and allowing for the influence of factors like income, etc., do not appear to differ significantly from those of random population samples. The purchase rates for the CU and population samples as a whole are of course quite different, as are the proportions of intenders, given comparable commodities and intentions questions. But there is no evidence that the interpretation of comparable intentions questions, or the behavior of households with a given response to a particular intentions question, differs for the CU sample and the population.

This can be seen in Table 7, where purchase rates for intenders and nonintenders in a random sample of the United States population are compared with those for the sample of Consumers Union member-subscribers analyzed above.

Although purchase rates in the CU sample tend to be higher than in the population both for intenders and nonintenders, the main disparity is in nonintender purchase rates. As I show in the next two chapters, differences in family income and life-cycle status have a pronounced relation to nonintender purchase rates but appear to have little or no relation to those of intenders. Thus, all of the important differences between the population and the CU sample can be readily explained by known differences in income (which is higher in the CU sample) and life-cycle status (more younger marrieds in the $\mathrm{CU}$ sample). Hence, there is no evidence that households in the CU sample differ from the population in their interpretation of intentions questions, and it can reasonably be argued that relationships found in this sample can be extrapolated to the population. 
TABLE 7

Consumers Union Sample Purghase Rates of Intenders and Nonintenders Compared with Purghase Rates in a Random Sample of the U.S. Population

Purchase Rate Observed

in Reinterview Survey

(per cent)

Intentions Question

Consumers

U.S. Union

Population Sample

\section{Automobile}

1. Plan to buy new car within 12 months

Yes, bought new or used within 12 months

No, bought new or used within 12 months

2. Definitely plan to buy new car within 12 months

Yes, bought new or used within 12 months

No, bought new or used within 12 months

3. Definitely, probably, possibly will buy new car within 12 months

Yes, bought new or used within 12 months

No, bought new or used within 12 months

4. Definitely, probably, possibly will buy new car within 12 months

Yes, bought new within 12 months

No, bought new within 12 months

5. Plan to buy new or used car within 6 months or within 12 months

Plan in 6 months, bought new or used in 12 months

Plan in 12 months, bought new or used in 12 months

No, bought new or used in 12 months

6. Plan to buy new or used car within 3 months

Yes, bought new or used within 3 months

No, bought new or used within 3 months

7. Plan to buy new or used car within 6 months

Yes, bought new or used within 6 months

No, bought new or used within 6 months

Refrigerator

8. Definitely plan to buy within 12 months

Yes, bought within 12 months

No, bought within 12 months

9. Definitely, probably, possibly will buy within 12 months Yes, bought within 12 months

Furniture

No, bought within 12 months

10. Definitely plan to buy within 12 months

Yes, bought within 12 months

No, bought within 12 months

11. Definitely, probably, possibly will buy within 12 months Yes, bought within 12 months

No, bought within 12 months
(1948)

67

13

(1948)

48

12

$(1958)^{\mathrm{a}}$

25

$(1958)^{\mathrm{B}}$

76

30

$(1958)^{\mathrm{a}}$

55

23

(1948)

(1959)

(1958)

Source: Consumers Union data from Table 2, above. Population data as follows. Line 1: Irving Schweiger, "Forecasting Short-term Consumer Demand From Consumer Anticipations," Journal of Business, April 1956, pp. 90-100. Lines 2, 3, 8, 9, 10, and 11: John B. Lansing and Stephen B. Withey, "Consumer Anticipations: Their Use in Forecasting Consumer Behavior," Short-Term Economic Forecasting, Princeton for NBER, 1955, pp. 381-453. Lines 5, 6, and 7: Federal Reserve Bulletin, September 1960, pp. 973-1003. Line 4: Peter De Janosi, "Factors Influencing the Demand for New Automobiles," Journal of Marketing, April 1959, pp. 412-418.

a Plans to buy new or used; about three-fourths are new.

b Bought new or used car, hence proportion identical to that shown in Question 3. 